Research Article

\title{
The Stability Evaluation of Shaft during Drastic Drawdown Dewatering of Alluvium
}

\author{
Mingze Du $\mathbb{D}^{1,}{ }^{1,2,3}$ Yanchun Xu, ${ }^{4}$ Heng Duan, ${ }^{4}$ and Wen $\mathrm{Li}^{1,2}$ \\ ${ }^{1}$ Mine Safety Technology Branch, China Coal Research Institute, Beijing 100013, China \\ ${ }^{2}$ State Key Lab of Coal Resource High Efficient Mining and Clean Utilization, China Coal Research Institute, \\ Beijing 100013, China \\ ${ }^{3}$ Liaoning Technical University, Fuxin 123000, China \\ ${ }^{4}$ School of Energy and Mining Engineering, China University of Mining and Technology, Beijing 100083, China \\ Correspondence should be addressed to Mingze Du; dumingze0910@163.com
}

Received 15 June 2019; Revised 24 September 2019; Accepted 8 October 2019; Published 30 October 2019

Guest Editor: Franco Concli

Copyright (c) 2019 Mingze Du et al. This is an open access article distributed under the Creative Commons Attribution License, which permits unrestricted use, distribution, and reproduction in any medium, provided the original work is properly cited.

The hydrophobicity of the aquifer at the bottom of the porous alluvium will affect the stability of the shaft. According to the changes of water level and the compressive amount of alluvium, we can evaluate the shaft stability and predict the shaft failure. In this work, the simulation model of the auxiliary shaft in the Zhuxianzhuang Coal Mine is generated by using the Nsdc software to evaluate the stability of the shaft during drastic drawdown dewatering. Based on the measured hydrophobic compression ratio in an adjacent coal mine, the compressive amounts of the strata near the main and auxiliary shafts in the Zhuxianzhuang Coal Mine are predicted under the condition of drastic drawdown dewatering, which will be $249.69 \mathrm{~mm}$ and $302.75 \mathrm{~mm}$, respectively. It is more likely that the shaft wall may fracture in the 15th day (fourth load level) under the condition of drastic drawdown dewatering. The formation compressive amount near the auxiliary shaft is approximately $320 \mathrm{~mm}$, which is close to the measured predicted value. At the same time, the Fisher discriminant model is established, and it is predicted that the state of the main and auxiliary shafts will be failure under the conditions of drastic drawdown dewatering in the Zhuxianzhuang Coal Mine. Based on the simulating results, the technical means of using the ground grouting for early prevention and control is proposed.

\section{Introduction}

The Huang-Huai region is an important coal production base in China. Usually there is an aquifer alluvium with a thickness greater than $100 \mathrm{~m}$. Since 1987, more than one hundred shaft walls have fractured one after another, and such disasters are still ongoing [1-3]. The shaft is the main road connecting the ground and the underground. The safety and stability of the shaft is related to the normal production and safe operation of the entire mine. On the one hand, the fracture of shaft wall is easy to cause concrete block falling off and endanger the safety of workers. On the other hand, it is easy to cause equipment damage, mine shutdown, and even accidents of water and sand inrush, resulting in heavy casualties and economic losses. Figure 1 shows shaft fracture in the Huang-Huai region.
After years of research, it is found that the shaft failure is related to the continuous hydrophobicity at bottom of the alluvial aquifer layer. The water level of aquifer at the bottom of the alluvial layer lowers caused by mining, which leads to the consolidation and compression of the alluvial strata, and the additional compressive stress on the shaft wall occurs, which leads to fracture of the shaft [4-9]. Figure 2 shows formation and deformation caused by aquifer hydrophobicity near the shaft. Based on the mechanism of shaft failure, the treatment methods of installing a wall ring, casing reinforcement, opening a pressure slot, grouting the surrounding strata, and injecting water to stable water level through boreholes are proposed to prevent and control shaft failure [10-15].

Due to the suddenness of the shaft wall fracture, the treatment after shaft fracture has the shortcomings of technical difficulties, high cost, and long time. In recent 


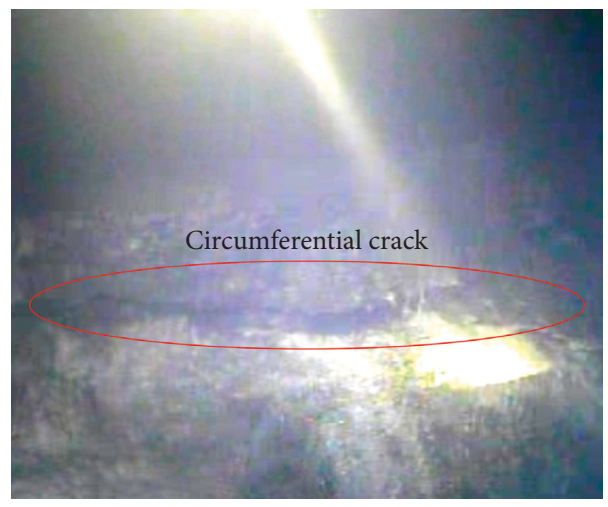

FIGURE 1: Shaft wall fracture in the Huang-Huai region.
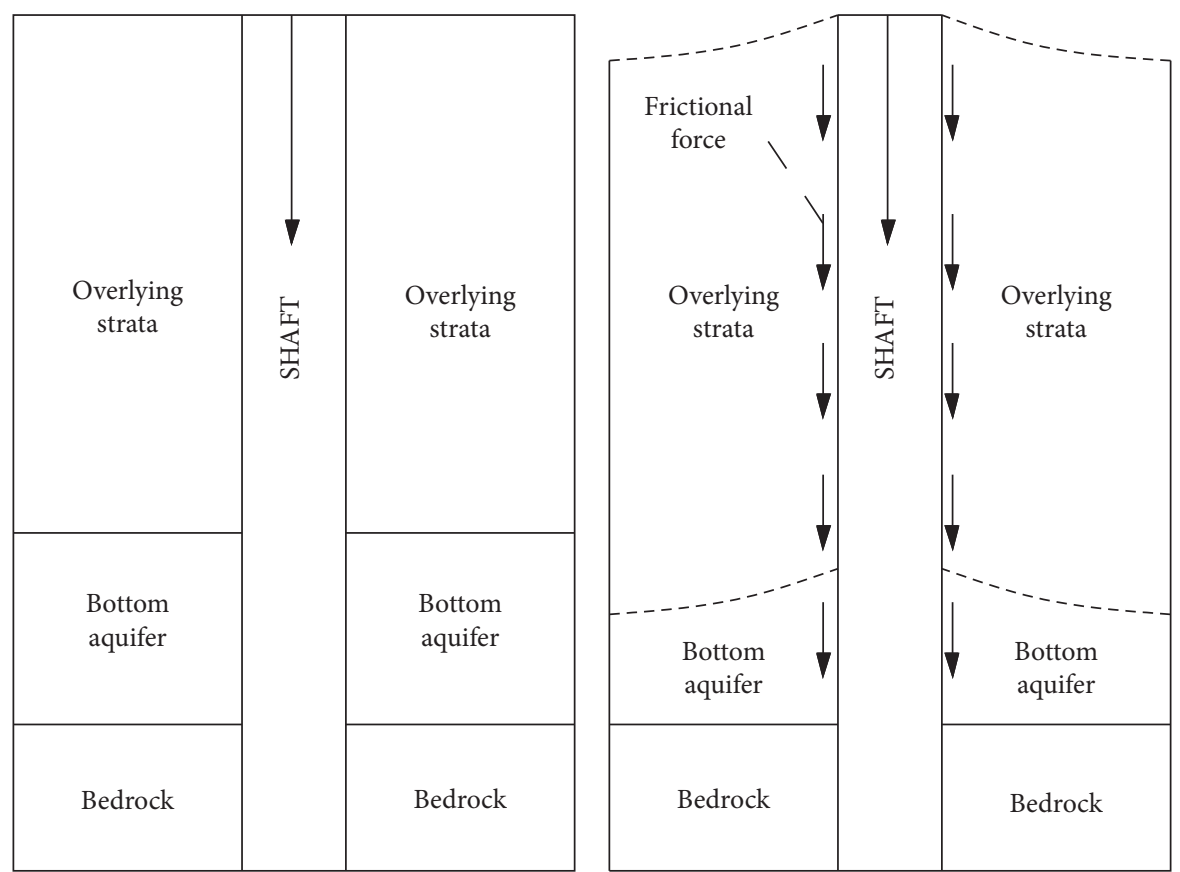

FIGURE 2: Deformation of the overlying quaternary strata around a shaft: (a) before continuous hydrophobicity at bottom of alluvial aquifer layer; (b) after continuous hydrophobicity at bottom of alluvial aquifer layer.

years, the mines usually use the priority to evaluate the stability of the shaft; that is, firstly, the stability of the shaft is evaluated according to the monitoring results of water level and formation compression, and then the treatment scheme of the shaft with near-term fracture possibility is worked out and selected. At present, many scholars have studied the shaft stability or surface subsidence caused by hydrophobicity of alluvial aquifers and obtained a series of results. In the aspect of shaft monitoring and prevention, in China, Huang et al. $[16,17]$ used a large shaft simulation test rig to conduct a test on the variation of the vertical additional force on the shaft wall during the drainage process and obtained that the vertical additional force increases with the aquifer pressure reduction. Meng et al. [18] studied the mechanism of shaft failure in the surface soil section of deep alluvium by theoretical analysis and numerical simulation based on the engineering background of shaft failure in the Huaibei Coalfield. It was concluded that the shaft failure was related to the depth of burial, water pressure of aquifer, and the weight of the soil enclosed in the shaft. Liang et al. $[19,20]$ studied the variations of strain in each stage of the shaft wall in detail by embedding an automatic stress-strain monitoring system on the shaft wall, analyzed the evolution characteristics of strain in the process of the shaft wall fracture, and obtained the characteristics of strain sudden increase when the shaft wall approached fracture. Taking Jining No. 3 Coal Mine as an example, Xu et al. [21] monitored the changes of water level and strain of the shaft wall during water injection and predicted the possible time of shaft wall fracture according to the monitoring results. 
Chai et al. [22] used the fiber Bragg grating technology to monitor the subsidence of formation in the process of dewatering and water injection and studied the relationship between the subsidence of formation and shaft stability. Outside of China, shaft failure is only caused by mining during construction or production, and there is no engineering example of shaft failure caused by hydrophobicity at the bottom of deep alluvium. The nonmining failure of the shaft is a special type of geological hazard in China. That is to say, the research mainly focuses on urban surface settlement caused by the hydrophobicity of underground aquifers, and there is no application in the prevention and control of the shaft outside of China [23-30]. In the prediction of shaft stability, many scholars take the measured data of shaft engineering as training samples, select many factors such as diameter of shaft, thickness of alluvium, and water level lower, and use many intelligent algorithms such as the neural network, genetic algorithm, and support vector machine to predict the stability of the shaft, which provides a basis for accurately evaluating the safety state of the shaft. Xu et al. [31, 32] considered the factors related to the fracture of the shaft and used the fuzzy clustering method to predict the safety state of the shaft in the Xinglongzhuang Coal Mine, and an evaluation system of shaft stability was established. Liu et al. [33] evaluated the stability of the shaft in the Dongtan Coal Mine by empirical analysis and fuzzy clustering and predicted the time when the shaft wall could be fracture. Gong and Li [34] used the distance discriminant method to predict the shaft stability in the Yanzhou mining region and compared the prediction results with those obtained by the neural network and fuzzy network method, which proved the accuracy of the method. Shao and Zhang [35] improved the KNN algorithm based on the combination technology and established a more accurate prediction model. Yuan et al. [36] established a prediction model based on the genetic-support vector machine and tested the engineering examples to obtain a model with high accuracy, which provided a new method for rapid and accurate prediction of the shaft stability.

In summary, most of the previous research studies focus on the monitoring of shaft stability and nearby strata compression and most of the conditions are that the alluvial aquifer is naturally slow and hydrophobic under mining conditions. However, there are few studies on the stability of the shaft under the condition of drastic drawdown dewatering and the previous intelligent prediction methods have some randomness and subjectivity, resulting in certain errors in prediction results.

In this study, first, according to the long-term measured data of the Xinglongzhuang Coal Mine in the adjacent mining area of the Zhuxianzhuang Coal Mine, the calculation model of formation compression in the subsoil layer is established. The surface subsidence near the shaft in the hydrophobic affected region of the Zhuxianzhuang Coal Mine is predicted by the engineering analogy method. Then, the stress state of the shaft and formation compression under different water levels drawdown are studied by numerical simulation, and the shaft stability is evaluated. At the same time, considering the main factors of shaft stability, the Fisher discriminant model is used to predict the stability of the shaft under the condition of drastic drawdown dewatering, and reasonable preventive and control measures are put forward.

\section{Interception and Drainage Project Introduction}

The Zhuxianzhuang Coal Mine is located in the eastern part of the Suzhou mining area of the Huaibei Coalfield with a production capacity of 2.45 million $\mathrm{t} / \mathrm{a}$. The alluvium in the Zhuxianzhuang Coal Mine has a structure of "four aquifers and three aquifuges" in the longitudinal direction, and the aquifer and the aquifuge are alternately interposed. The Jurassic glutenite aquifer (the fifth aquifer) below the alluvial stratum covers a large area of no. 8, no. 10 coal seams, too ash and Ordovician ash aquifers, with an angular unconformity contact relationship. The upper part of the fifth aquifer is a layer of Jurassic sandstone with good water-resisting property, which is unconformly overlaid on the Jurassic strata. The fifth aquifer strip is partially in direct contact with the fourth aquifer. The relationship between the aquifers is shown in Figure 3.

Previous dewatering test showed that there was obvious hydraulic connection between the fifth aquifer and the fourth aquifer, too ash and Ordovician limestone aquifers, and the vertical and lateral recharge conditions are good, which threatens the safe mining of no. 8 coal seam in the northern part of the mine. On January 30, 2015, a water inrush accident occurred in the 866-1 working face. The analysis showed that the water source comes from the fifth aquifer, and the fourth aquifer, too ash and Ordovician limestone aquifers were involved in replenishment. Considering the Ordovician limestone aquifer, the water volume is huge, and the mining of no.8 coal seam will lead to its continuous recharge to the fifth aquifer. The use of conventional underground water prevention measures is far from ensuring safe mining. Therefore, the Zhuxianzhuang Coal Mine adopts the comprehensive water inrush control measures by first constructing a wall to cut off the connection between the fifth aquifer and other aquifers, then dewatering, and finally mining. The engineering design plan of the " $\mathrm{L}$ "-shaped curtain blocking the fifth aquifer is shown in Figure 4.

However, the large-scale dewatering of the fifth aquifer will inevitably lead to drastic drawdown dewatering of the fourth aquifer, resulting in consolidation and compression of the alluvial soil layer, and sedimentation will spread to the surface, which may cause shaft failure within the dredging area. According to the numerical simulation results of GMS (Grounder Modeling Systems), the water level drawdown of the fourth aquifer caused by the fifth aquifer dewatering could reach $118 \mathrm{~m}$ within one year, and the water level drawdown could reach $114 \mathrm{~m}$ in the first month. Therefore, it is necessary to analyze and predict the surface settlement near the shaft, and evaluate the stability of the shaft so as to take targeted preventive and control measures. 


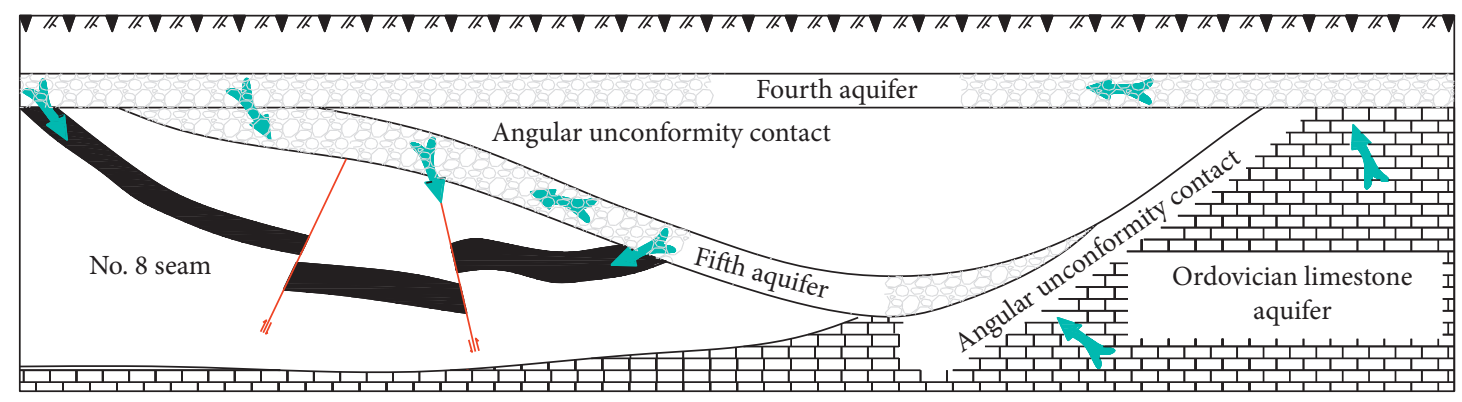

FIgURE 3: The relationship between the aquifers.

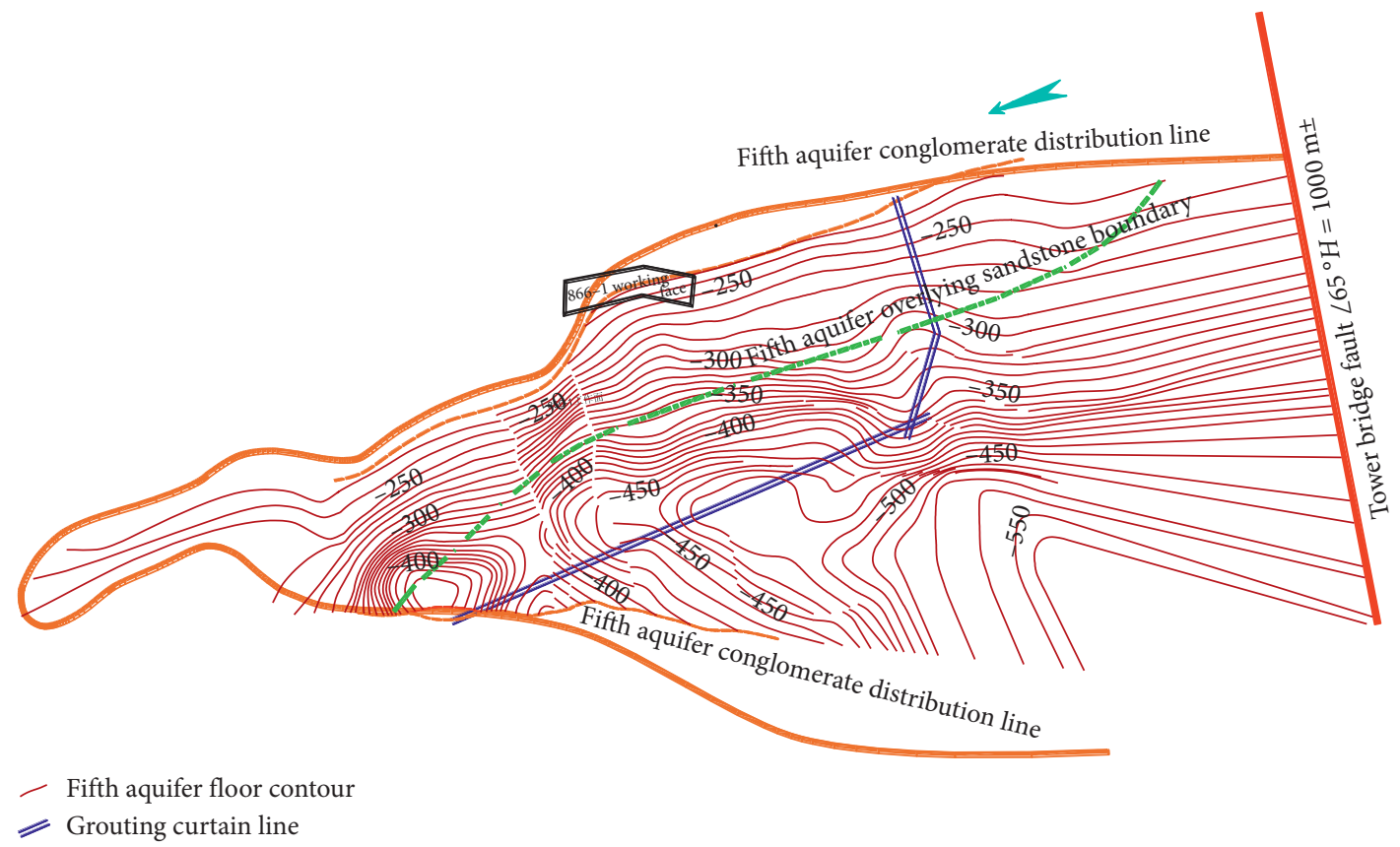

Figure 4: The engineering design plan of the " $\mathrm{L}$ "-shaped curtain blocking the fifth aquifer.

\section{Numerical Simulation of Shaft Stability}

3.1. Model Establishment and Mechanical Parameters. In this numerical simulation, NM2dc numerical simulation software (China Copyright Administration Computer Copyright Registration No. 2008SRBJ3213) compiled by Tsinghua University is used. The simulation software can simulate the common consolidation deformation and stress and strain problems of geotechnical engineering. The calculation results can be called by Tecplot software, so that the simulation results can be displayed more intuitively and vividly.

Because the thickness of alluvium in the Zhuxianzhuang Coal Mine is large, the nature of soil are different and the properties of the bedrock weathering zone, shaft wall, and soil material are completely different; therefore, different lithological materials are selected in the appropriate constitutive model. According to the engineering properties of the soil, the mechanical properties of the bedrock weathering zone and the shaft wall, the Duncan-Zhang model is selected for the simulated soil layer, and the linear elastic model is selected for the shaft wall and bedrock weathering zone.
Biot's consolidation theory is used in the model to analyze the consolidation or expansion process of the soil layer.

Taking the auxiliary shaft in the Zhuxianzhuang Coal Mine as an example, the simulated radial width is from the central axis of the shaft to $200 \mathrm{~m}$ and the depth is $9 \mathrm{~m}$ below the surface to the bedrock weathering zone, and the depth is $260 \mathrm{~m}$. The calculation model is shown in Figure 5. The number of nodes in the model is 1155 , and the number of units is 1088. In the model, the $x$-axis represents the distance from the axis of the shaft, which is the radius $(\mathrm{m})$ and the $y$ axis represents the formation height $(\mathrm{m})$, and the uppermost end of the $y$-axis is the surface. Figure 5 shows the calculation model of the auxiliary shaft in the Zhuxianzhuang Coal Mine. The auxiliary shafts in the Zhuxianzhuang Coal Mine are constructed by the freezing method, and the inner diameter and outer diameter of the auxiliary shaft are $2.9 \mathrm{~m}$ and $3.25 \mathrm{~m}$, respectively. The strength of concrete is C25C40. The stress state of the shaft and the compression of the formation under the condition of drastic drawdown dewatering are analyzed. The parameters of the shaft wall, strata, and interface are shown in Tables 1 and 2 . 


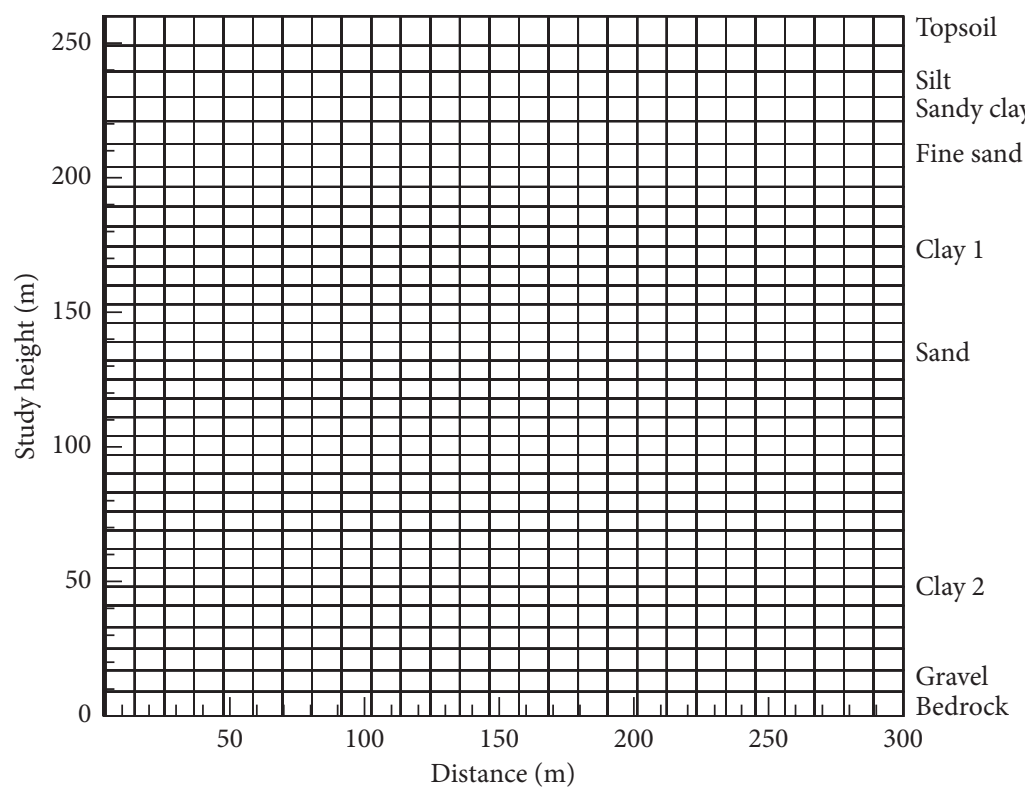

(a)

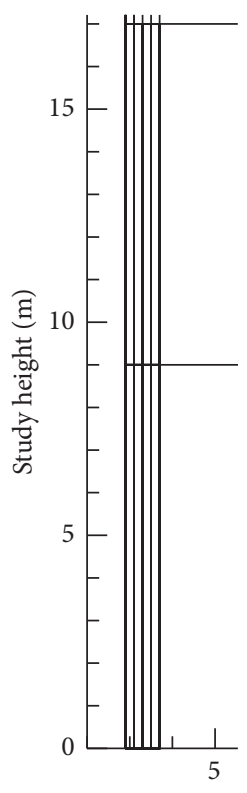

(b)

Figure 5: (a) Calculation model of the auxiliary shaft in the Zhuxianzhuang Coal Mine and (b) local enlargement of the shaft wall.

3.2. Simulation Scheme. According to the previous GMS numerical simulation results, the water level of the fourth aquifer near the auxiliary shaft decreased by $114 \mathrm{~m}$ in the first month, and the water level decreased by $118 \mathrm{~m}$ in one year. Based on this, the simulation scheme of drastic drawdown dewatering is designed (see Table 3 ) to analyze the stress of the shaft wall and formation deformation.

\subsection{Numerical Simulation Results and Analysis}

3.3.1. Analysis of the Stress State of the Shaft Wall. Figure 6 shows the vertical stress state of the shaft wall under different load levels, and Figure 7 shows the variation of water level drainage and vertical stress of the shaft wall with load level. As can be seen from Figures 6 and 7, the water level of the fourth aquifer dropped sharply in one month (the first five load levels) and the vertical stress of the shaft wall increased sharply, and the greater the water level decreases, the greater the vertical stress of the shaft wall. When the load level is the third load level, the vertical stress of the shaft wall at the bottom of alluvium is close to $20 \mathrm{MPa}$. When the load level is the fifth load level, the vertical stress of the shaft wall at the bottom of alluvium reaches $70 \mathrm{MPa}$, which exceeds the strength of the shaft wall (C20-C40), and the possibility of the shaft failure is large. In the following 11 months, the water level dropped by $4 \mathrm{~m}$, and the vertical stress of the shaft wall increased; however, the increment of stress is relatively small. When the load level is the ninth load level, the vertical stress at the bottom of alluvium is close to $80 \mathrm{MPa}$.

3.3.2. Analysis of Formation Compression Deformation. Figure 8 shows the compression deformation of the strata near the shaft under different load levels. As can be seen from Figure 8, with the drop of water level, the surface subsides as a "pan." Near the shaft wall, due to the supporting effect of the shaft wall on the soil layer, the shaft wall and the soil layer shear each other and the soil layer bends. With the distance from the shear zone, the soil layer is weakened by the supporting effect of the shaft wall, and the formation settlement increases. At the same time, it can also be seen that the greater the water level drawdown, the greater the compression deformation, and the greater the accumulation of formation subsidence. When the load level is the fourth load level, the compressive amount of strata is approximately $150 \mathrm{~mm}$. When the load level is the fifth load level, the compressive amount of strata is approximately $180 \mathrm{~mm}$. In the following 11 months, the water level drops by $4 \mathrm{~m}$, and the formation compression increases; however, the increment of strata compression is relatively small. When the load level is the ninth load level, the compressive amount of strata is approximately $320 \mathrm{~mm}$.

\section{Measurement and Prediction of Formation Compression near the Shaft}

4.1. Calculation Model of Formation Compression. The structure, thickness, water level drawdown, and lithology of alluvial strata in different locations are significantly different. The more accurate prediction method is based on the detailed stratigraphic structure and lithology in the borehole column diagram and then stratified calculation. The principle of the calculation model of formation compression is to calculate the compression ratio of different lithological soil layers, and then establish the stratum compression model, respectively. By summing the compression amounts of the soil layers, the calculation formula of compression 


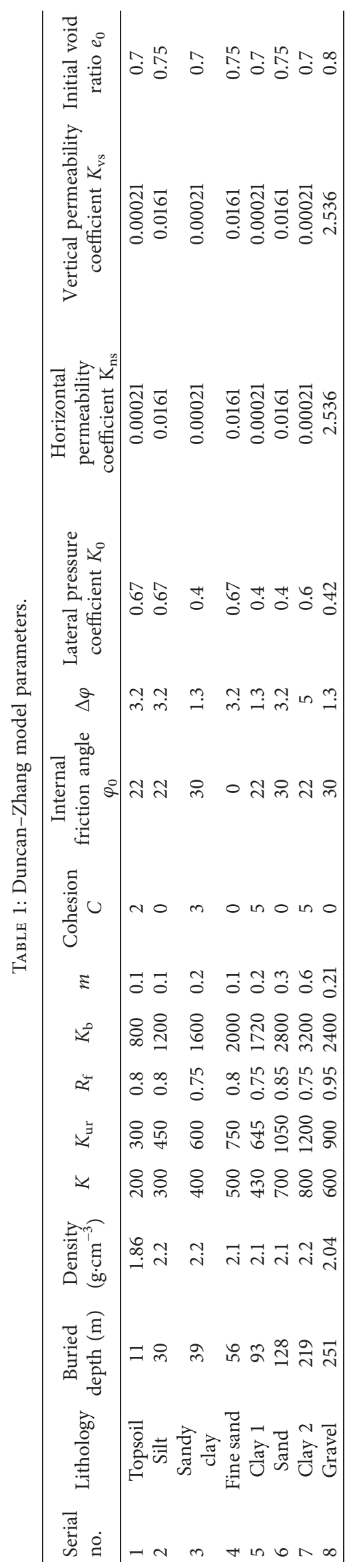


TABLE 2: Linear elastic model parameters of the well wall and weathering zone.

\begin{tabular}{|c|c|c|c|c|c|c|c|c|c|}
\hline $\begin{array}{l}\text { Serial } \\
\text { no. }\end{array}$ & Lithology & $\begin{array}{c}\text { Buried } \\
\text { depth } \\
(\mathrm{m})\end{array}$ & $\begin{array}{l}\text { Density } \\
\left(\mathrm{g} \cdot \mathrm{cm}^{-3}\right)\end{array}$ & $\begin{array}{c}\text { Elastic } \\
\text { modulus } E \\
(\mathrm{MPa})\end{array}$ & $\begin{array}{l}\text { Poisson's } \\
\text { ratio }\end{array}$ & $\begin{array}{c}\text { Lateral } \\
\text { pressure } \\
\text { coefficient } K_{0}\end{array}$ & $\begin{array}{c}\text { Horizontal } \\
\text { permeability } \\
\text { coefficient } K_{\mathrm{ns}}\end{array}$ & $\begin{array}{c}\text { Vertical } \\
\text { permeability } \\
\text { coefficient } K_{\mathrm{vs}}\end{array}$ & $\begin{array}{c}\text { Initial } \\
\text { void ratio } \\
e_{0}\end{array}$ \\
\hline 9 & Bedrock & 260 & 2.5 & 25000 & 0.25 & 0.19 & $7.5 \times 10^{-5}$ & $7.5 \times 10^{-5}$ & 0.21 \\
\hline 10 & $\begin{array}{c}\text { Shaft } \\
\text { wall }\end{array}$ & & 2.4 & 25000 & 0.167 & & & & \\
\hline
\end{tabular}

TABLe 3: The load level of the calculation scheme.

\begin{tabular}{lccccc}
\hline Load level & Depth of water table $(\mathrm{m})$ & Water level difference $(\mathrm{m})$ & Days $(\mathrm{d})$ & Water level change rate $\left(\mathrm{m} \cdot \mathrm{d}^{-1}\right)$ & Cumulative time $(\mathrm{d})$ \\
\hline 1 & 76.1 & 0 & 0 & 0 & 0 \\
2 & 81.1 & -5 & 1 & -5.00 & 1 \\
3 & 111.1 & -30 & 6 & -5.00 & 7 \\
4 & 144.1 & -33 & 8 & -4.13 & 15 \\
5 & 190.1 & -46 & 15 & -3.07 & 30 \\
6 & 191.1 & -1 & 60 & -0.02 & 90 \\
7 & 192.1 & -1 & 90 & -0.01 & 270 \\
8 & 193.1 & -1 & 90 & -0.01 & 365 \\
9 & 194.1 & -1 & 95 & -0.01 & \\
\hline
\end{tabular}

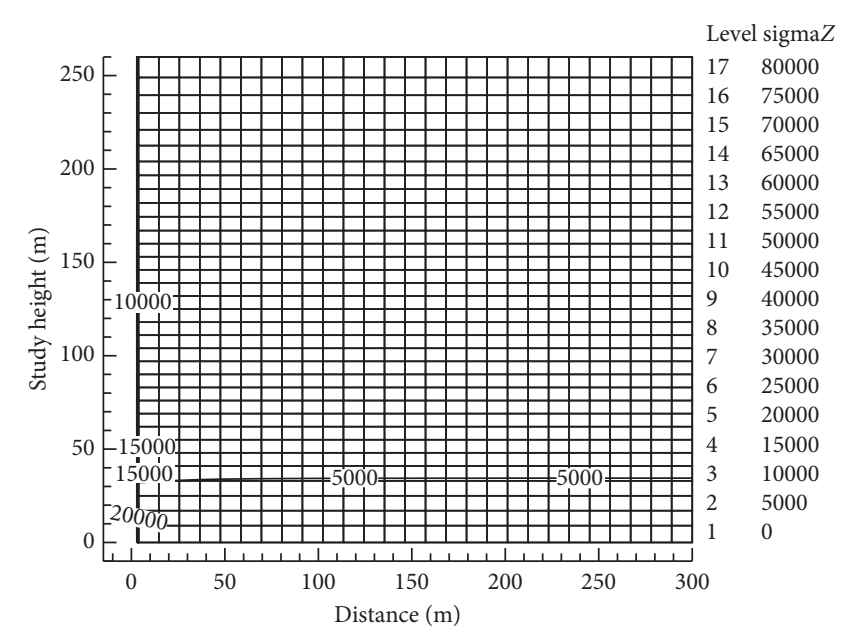

(a)

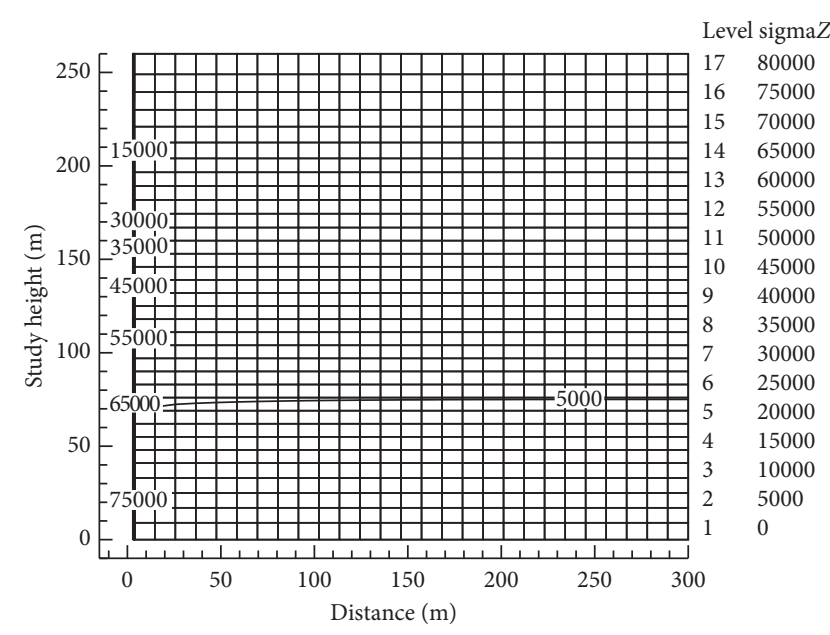

(c)

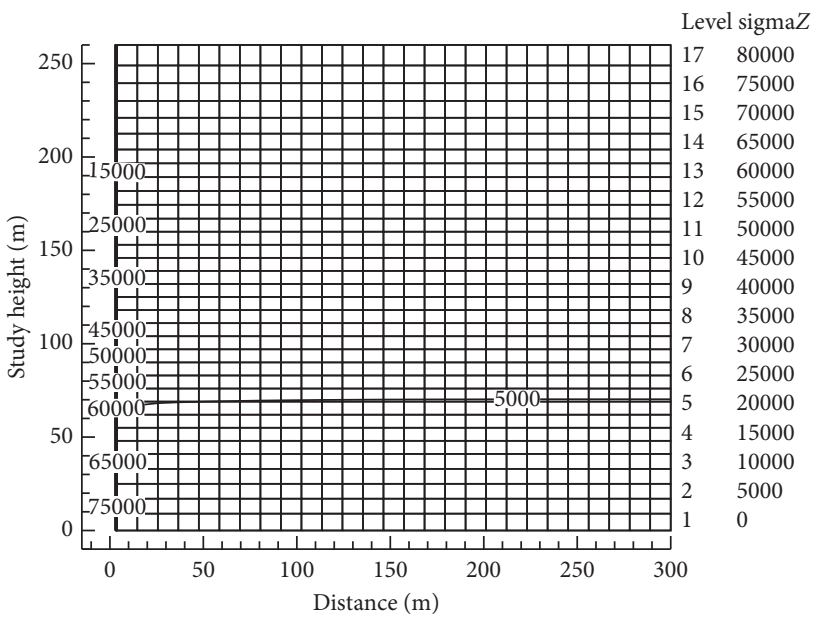

(b)

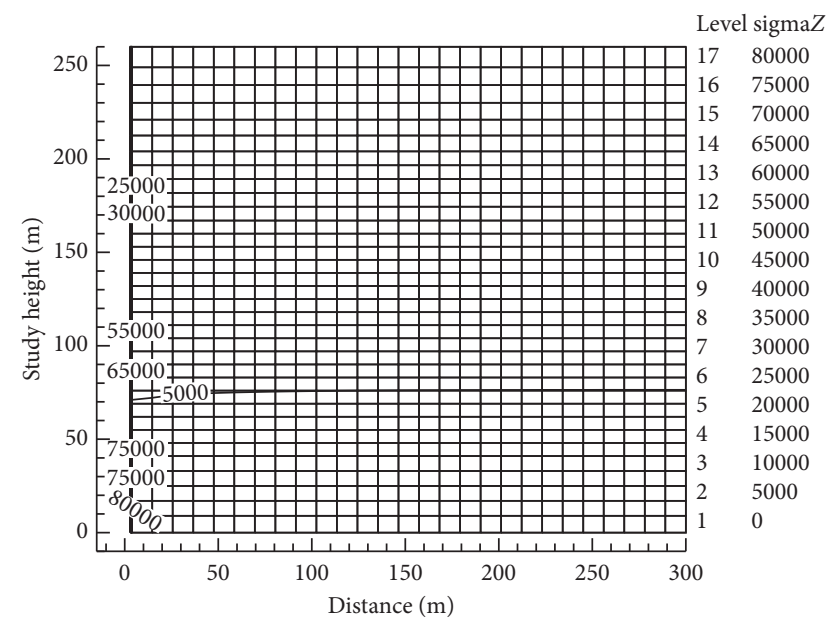

(d)

FigURE 6: Vertical stress state of the shaft wall under different load levels: (a) third load level; (b) fifth load level; (c) seventh load level; (d) ninth load level (stress unit $\mathrm{KPa}$ ). 


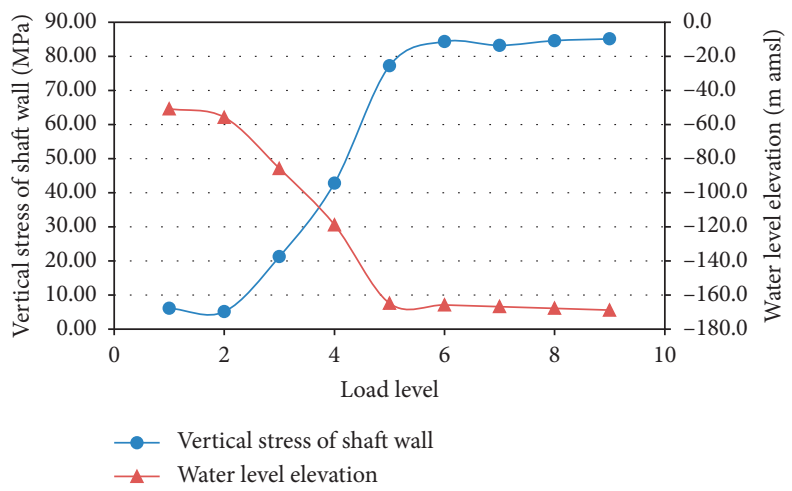

FiguRE 7: Variation of water level drainage and vertical stress of the shaft wall with load level.

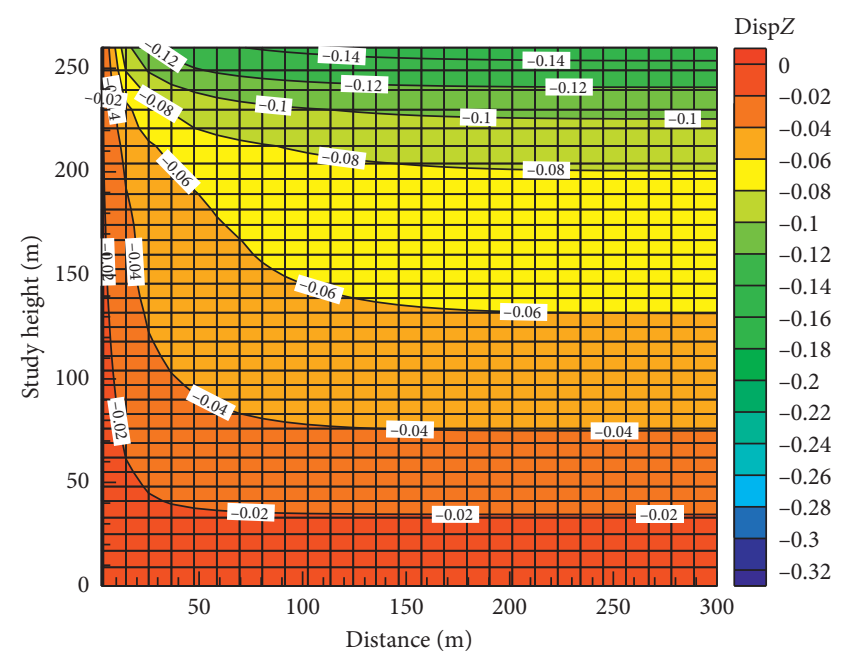

(a)

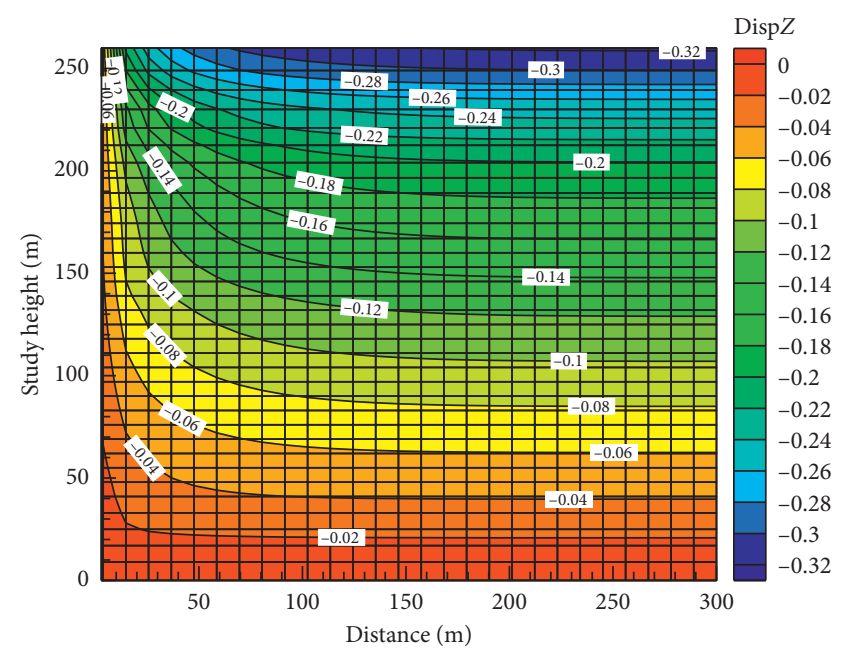

(c)

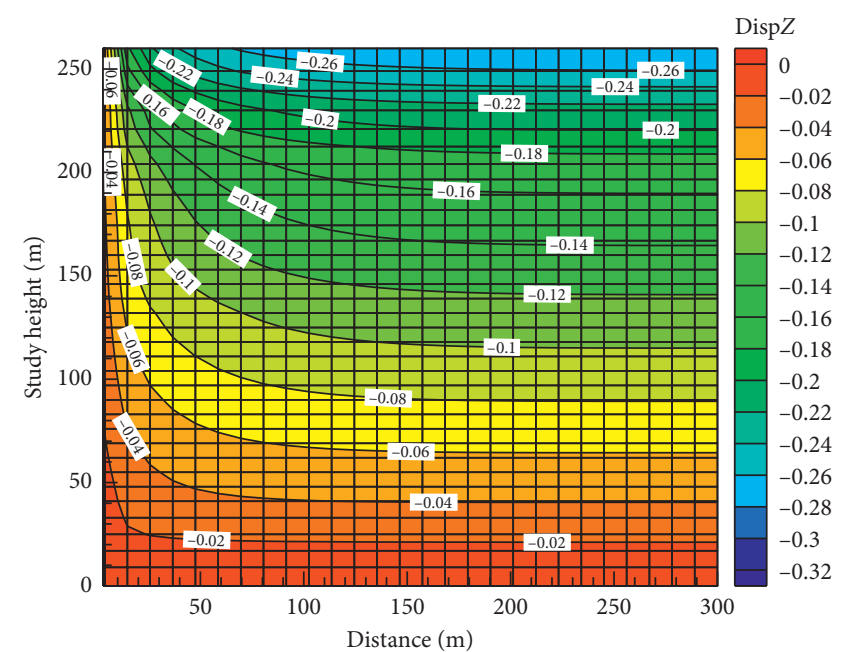

(b)

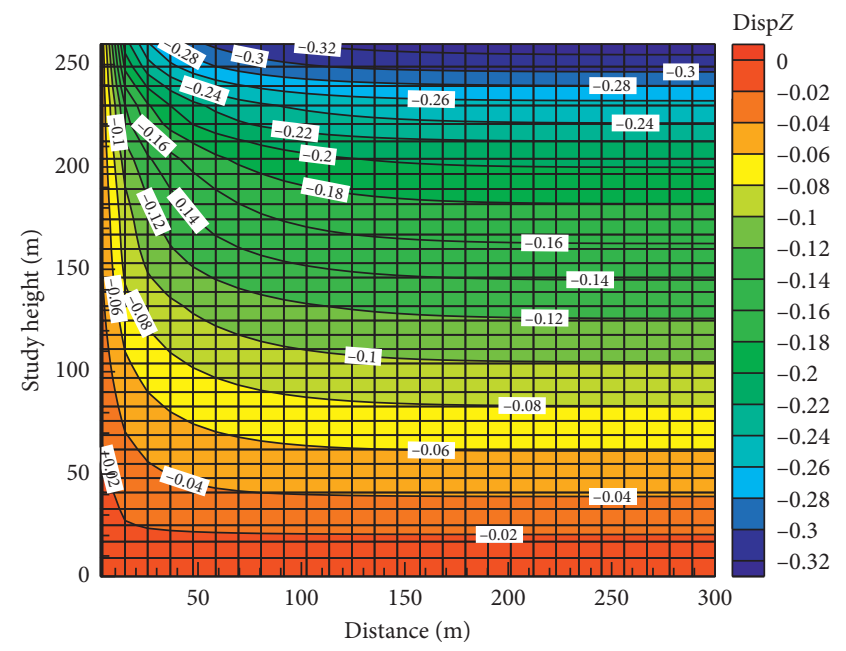

(d)

Figure 8: The compression deformation of the formation near the shaft under different load levels: (a) fourth load level; (b) fifth load level; (c) seventh load level; (d) ninth load level.

deformation of the entire formation can be obtained. The formula for calculating the compression ratio of each soil layer is as follows:

$$
\Delta S_{i}=M_{i} H_{i} \Delta P
$$

In the formula, $\Delta S_{i}$ is the compression ratio of different lithological soil layers, $\mathrm{m}, M_{i}$ is the compressibility of different lithological soil layers, $\mathrm{m} / \mathrm{m}^{2}, H_{i}$ is the thickness of different lithological soil layers, $\mathrm{m}$, and $\Delta P$ is the water level drop, $m$. 
The compression deformation of alluvium is the sum of $n$-layer compression and $S$, and the calculation formula is as follows:

$$
S=\sum_{i=1}^{n} \Delta S_{i} .
$$

Because there is a large thickness and stable distribution of the third aquifuge in the upper part of the fourth aquifer in the Zhuxianzhuang Coal Mine, which isolates the hydraulic connection between the first, second, and third aquifers and the fourth aquifer. Therefore, the first, second, and third aquifers have no direct impact on mine water filling, so only the deformation of each soil layer in the fourth aquifer group is considered.

Both the Xinglongzhuang Coal Mine and the Zhuxianzhuang Coal Mine are located in the Huang-Huai region, and alluvial strata are similar. Considering that no observation of stratum compression has been carried out near the shafts in the Zhuxianzhuang Coal Mine in recent years, the engineering analogy method is used to predict the compression amount of the alluvium in the Zhuxianzhuang Coal Mine based on the compression ratio at the bottom of the alluvial aquifer group. The measured data of the compressive amount of the formation near the west ventilation shaft in the Xinglongzhuang Coal Mine is selected. The compression process at the bottom of alluvial strata is shown in Figure 9. According to the variation of thickness and water level of the third aquifer sand layer, the data of the stable time interval (October, 2015-October, 2016) is selected as the basic data of the fitting formula, and the compression ratio of each stratum is calculated. The results are shown in Figure 10.

Figure 11 shows the linear regression between compression ratio of strata near the west ventilation shaft and time in the Xinglongzhuang Coal Mine. The linear regression started on October 13, 2015, and is the zero point of the $x$-axis. The measurements started a few months after the start date. According to the fitting relationship of statistical monthly compression ratio and time, the compression ratio of the hydrophobic formation on January 18, 2018, in the Zhuxianzhuang Coal Mine can be calculated. The calculation results are shown in Table 4.

4.2. Prediction Results of Formation Compression near the Shafts. According to the structure and thickness of the aquifer at the bottom of the alluvium, combined with the water level drop near the shafts of the hydrophobic scheme and the compression ratio of each layer, the compressive amounts of the strata near the main and auxiliary shafts in the Zhuxianzhuang Coal Mine are obtained by substituting the calculation model of the compression of the formation. Prediction results of strata compression near the main and auxiliary shafts in the Zhuxianzhuang Coal Mine are showed in Table 5. Then, using the same method to calculate the remaining 11 months, the water level dropped by $4 \mathrm{~m}$, and the compressive amounts of the formation near the main and auxiliary shafts are $8.47 \mathrm{~mm}$ and $10.27 \mathrm{~mm}$, respectively. Therefore, the cumulative compressive amounts of the formation near the main and auxiliary shafts caused by the

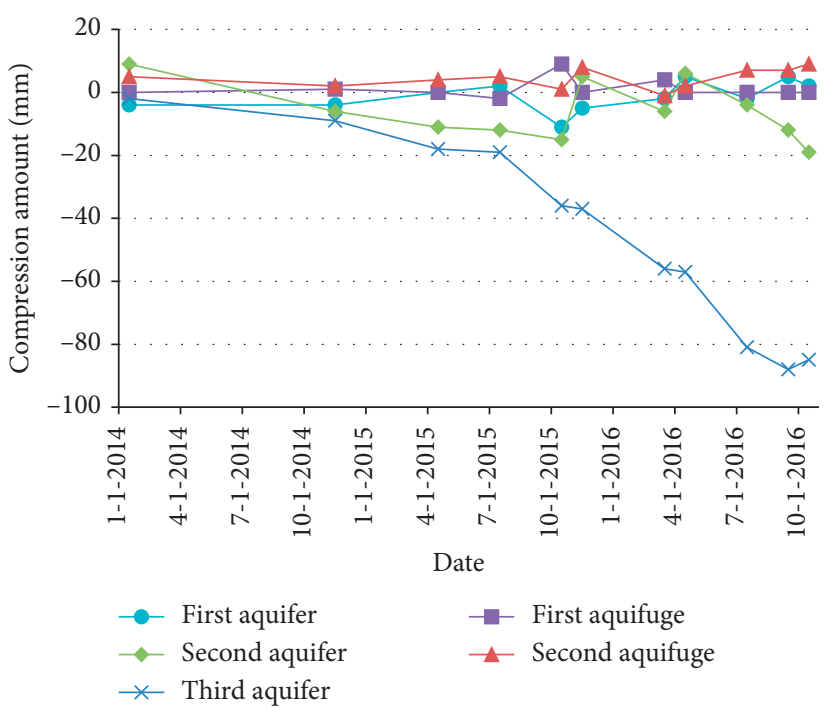

FIgURE 9: Compression process of alluvial strata near the west ventilation shaft in the Xinglongzhuang Coal Mine.

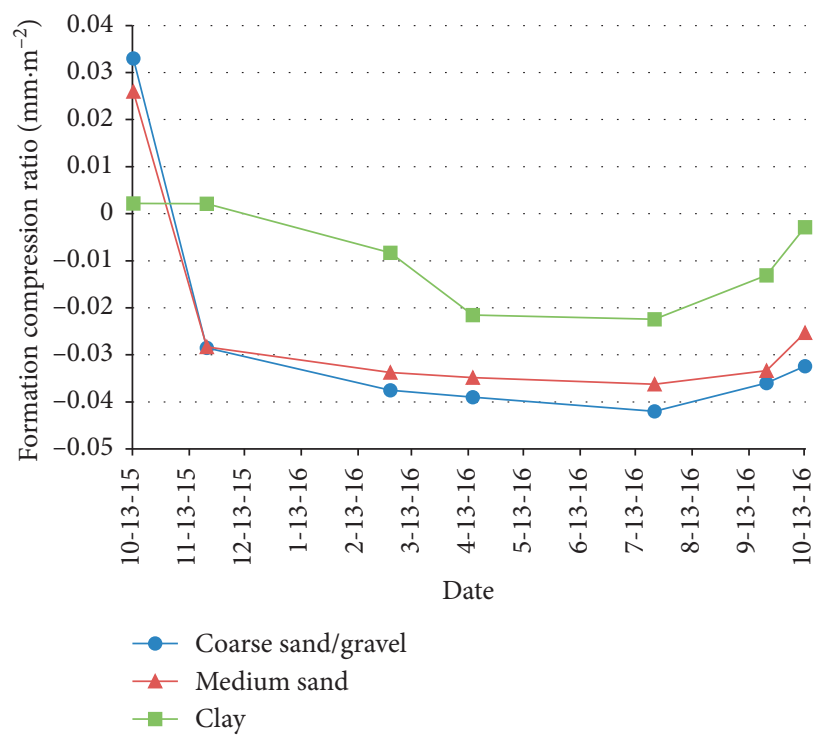

Figure 10: Compression rate of strata near the west ventilation shaft in the Xinglongzhuang Coal Mine.

fifth aquifer dewatering in the Zhuxianzhuang Coal Mine would be $249.69 \mathrm{~mm}$ and $302.75 \mathrm{~mm}$, respectively.

In the numerical simulation, the strata compression near the auxiliary shaft is approximately $320 \mathrm{~mm}$, which is close to the predicted value of strata compression $(302.75 \mathrm{~mm})$, indicating that the simulation results are reliable.

\section{Fisher Discriminant Model for Evaluation of Shaft Stability}

5.1. Analysis of Main Controlling Factors Affecting Shaft Failure

(1) Surface Subsidence Velocity $\left(x_{1}\right)$. Surface subsidence is the result of formation compression. The faster the 


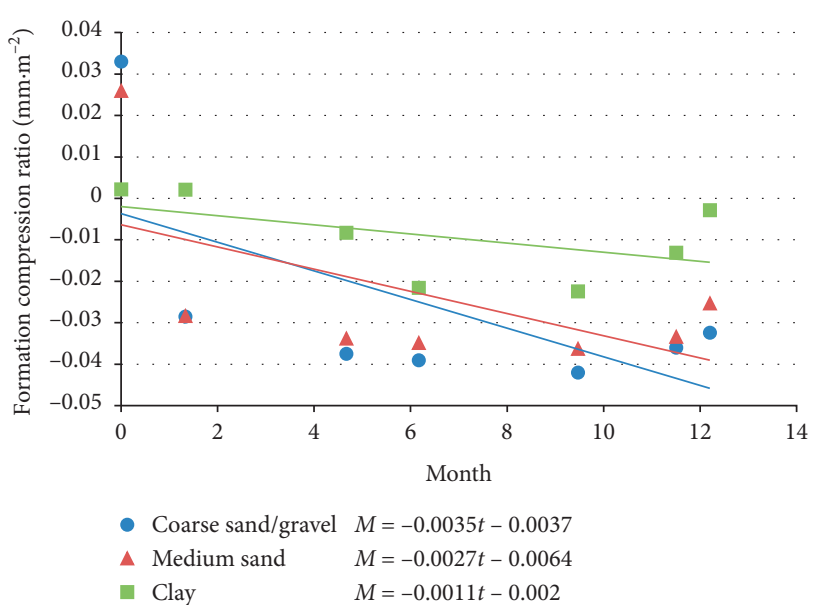

Figure 11: Compression rate of the west ventilation shaft in the Xinglongzhuang Coal Mine.

TABle 4: Prediction of formation compression ratio of industrial plaza in the Zhuxianzhuang Coal Mine.

\begin{tabular}{lc}
\hline Lithology & Formation compression ratio $\left(\mathrm{mm} \cdot \mathrm{m}^{-2}\right)$ \\
\hline Coarse sand/gravel & 0.100 \\
Medium sand & 0.081 \\
Clay & 0.032 \\
\hline
\end{tabular}

formation compression rate, the greater the possibility of shaft failure.

(2) Cumulative Surface Subsidence $\left(x_{2}\right)$. The cumulative subsidence of the surface is the sum of the cumulative compression values of the formation. The larger the cumulative subsidence of the surface, the greater the cumulative strain of the interaction between the formation and shaft, and the greater the possibility of shaft failure.

(3) Burial Depth of Main Compression Layer $\left(x_{3}\right)$. On the one hand, the greater the depth of the main compression layer, the greater the thickness of alluvial stratum, the greater the contact area between the shaft and the soil layer, and the higher the risk of the shaft. On the other hand, the greater the depth of the main compression layer, the thicker the overlying soil layer, the greater the additional stress, and the greater the possibility of shaft failure.

(4) Net Shaft Diameter $\left(x_{4}\right)$. From the knowledge of elasticity mechanics, it can be seen that the larger the net diameter of the shaft, the larger the contact area between the soil layer and the shaft, the greater the additional stress, and the greater the possibility of shaft failure.

(5) Shaft Wall Thickness Factor $\left(x_{5}\right)$. The thicker the shaft wall is, the higher the compressive strength of the borehole is, and the greater the additional stress required for the shaft wall to be fractured. Therefore, the greater the wall thickness, the less the possibility of shaft failure.

(6) Construction Method $\left(x_{6}\right)$. The shaft failure in the Huang-Huai region is mostly constructed by the freezing method, and the shaft constructed by the drilling method is also failure. However, compared with the freezing method, the drilling method takes longer time from shaft construction to failure, and the drilling method is superior to the freezing method. In the shaft stability evaluation, freezing method is defined as 0 and drilling method is defined as 1 .

(7) Shaft Construction Quality and Shaft Tower Factors $\left(x_{7}\right)$. The construction quality of the shaft wall is directly related to the strength of the shaft wall. The position of the shaft tower also has an impact on the shaft failure. The shaft tower is located on the surface of the shaft, which is beneficial to the stability of the shaft, while the shaft tower is located on the derrick, and the possibility of fracture of the shaft wall is relatively larger. In the shaft stability evaluation, the tower is defined as 0 on the ground and 1 on the wall.

\subsection{Fisher Discrimination Method Introduction}

5.2.1. Basic Idea of Fisher. Taking two groups of samples as an example, the measured data of the samples with $p$ influencing factors are selected and a discriminant function relation is established according to the idea of variance analysis: $y=c_{1} x_{1}+c_{2} x_{2}+\cdots+c_{p} x_{p}$, where coefficients $c_{1}, c_{2}, \ldots, c_{p}$ follow the basic principle of maximizing the difference between two groups and minimizing the dispersion in each group. According to the established discriminant function, the $p$ influencing factors of the sample to be tested are substituted into the discriminant function formula to obtain the $y$ value and the obtained $y$ value is compared with the discriminant critical value, and the samples to be tested are classified according to results of the comparison.

5.2.2. Discriminant Function and Criterion. For the two groups of samples $G_{1}$ and $G_{2}, n_{1}$ samples are selected from the first group of samples and $n_{2}$ samples are selected from the second group of samples, and $p$ influencing factors are selected from each sample for field measurement. Based on the measured results, the functional relationship $y=c_{1} x_{1}+$ $c_{2} x_{2}+\cdots+c_{p} x_{p}$ is established and the samples to be measured are substituted into the functional relationship. The formulas are as follows:

$$
\begin{aligned}
& y_{i}^{(1)}=c_{1} x_{i 1}^{(1)}+c_{2} x_{i 2}^{(1)}+\cdots+c_{p} x_{i p}^{(1)} \quad i=1,2, \ldots, n_{1}, \\
& y_{i}^{(2)}=c_{1} x_{i 1}^{(2)}+c_{2} x_{i 2}^{(2)}+\cdots+c_{p} x_{i p}^{(2)} \quad i=1,2, \ldots, n_{2} .
\end{aligned}
$$

The two sides of equations (3) and (4) are added separately, and the results are as follows: 
TABle 5: Prediction results of strata compression a month near the main and auxiliary shafts in the Zhuxianzhuang Coal Mine.

\begin{tabular}{|c|c|c|c|c|c|c|c|}
\hline Location & Lithology & $\begin{array}{l}\text { Buried depth } \\
\qquad(\mathrm{m})\end{array}$ & $\begin{array}{l}\text { Thickness } \\
\text { (m) }\end{array}$ & $\begin{array}{l}\text { Water level } \\
\text { drop }(\mathrm{m})\end{array}$ & $\begin{array}{l}\text { Formation compression ratio } \\
\qquad\left(\mathrm{mm} \cdot \mathrm{m}^{-2}\right)\end{array}$ & $\begin{array}{c}\text { Formation } \\
\text { compression }(\mathrm{mm})\end{array}$ & $\begin{array}{c}\text { Strata } \\
\text { compression } \\
(\mathrm{mm})\end{array}$ \\
\hline \multirow{4}{*}{ Main shaft } & Silt & $231.60-236.50$ & 4.90 & 114 & 0.081 & 45.25 & \multirow{4}{*}{241.22} \\
\hline & $\begin{array}{l}\text { Clay } \\
\text { sand }\end{array}$ & $236.50-242.80$ & 6.30 & 114 & 0.081 & 58.17 & \\
\hline & Clay & $242.80-246.20$ & 3.40 & 114 & 0.032 & 12.40 & \\
\hline & Gravel & $246.20-257.20$ & 11.00 & 114 & 0.100 & 125.40 & \\
\hline \multirow{3}{*}{$\begin{array}{l}\text { Auxiliary } \\
\text { shaft }\end{array}$} & $\begin{array}{l}\text { Clay } \\
\text { sand }\end{array}$ & $237.51-243.03$ & 5.52 & 114 & 0.081 & 50.97 & \multirow{3}{*}{292.48} \\
\hline & $\begin{array}{l}\text { Clay } \\
\text { sand }\end{array}$ & $243.03-251.11$ & 8.08 & 114 & 0.081 & 74.61 & \\
\hline & Gravel & 251.11-265.75 & 14.64 & 114 & 0.100 & 166.90 & \\
\hline
\end{tabular}

$\bar{y}^{(1)}=\sum_{k=1}^{p} C_{k} \bar{X}_{k}^{(1)}$, means of the first group of samples, $\bar{y}^{(2)}=\sum_{k=1}^{p} C_{k} \bar{X}_{k}^{(2)}$, means of the second group of samples.

To give full play to the discriminant function, it is necessary to maximize the difference of each group. Therefore, it is required that, (1) for the mean of the two groups $\bar{y}^{(1)}$ and $\bar{y}^{(2)}$, the larger the difference, the better and (2) for the same group of samples $\bar{y}^{(1)}\left(i=1, \ldots, n_{1}\right)$, the smaller the group $\sum_{i=1}^{n_{1}}\left(y_{i}^{(1)}-\bar{y}_{(1)}\right)^{2}$, the better. Similarly, the relationship within the other group $\sum_{i=2}^{n_{1}}\left(y_{i}^{(2)}-\bar{y}_{(2)}\right)^{2}$ is as small as possible.

After the discriminant function is established, the $y$ value of each group is obtained. At this time, a critical value needs to be compared with it, that is, the critical value $y_{0}$ of discriminant function needs to be determined. Usually, $y_{0}$ passes through the weighted average of two sets of values, that is, the weighted average of $\bar{y}^{(1)}$ and $\bar{y}^{(2)}$ :

$$
y_{0}=\frac{n_{1} \bar{y}^{(1)}+n_{2} \bar{y}^{(2)}}{n_{1}+n_{2}} .
$$

Assuming that $\bar{y}^{(1)}$ and $\bar{y}^{(2)}$ obtained from the measured data satisfy $\bar{y}^{(1)}>\bar{y}^{(1)}$, the criterion of the discriminant function is as follows: substituting the sample $X=\left(x_{1}, x_{2}, \ldots, x_{p}\right)^{\prime}$ into the discriminant function and calculating the $y$ value, if $y>y_{0}, X \in G_{1}$ is determined while $y<y_{0}, X \in G_{2}$ is determined. Assuming that $\bar{y}^{(1)}<\bar{y}^{(2)}$, the criterion of the discriminant function is as follows: if $y>y_{0}$, then $X \in G_{2}$ is determined while if $y<y_{0}, X \in G_{1}$ is determined.

5.2.3. Discriminant Results and Analysis of Shaft Stability. According to the data collected by the author, 11 sets of measured data from the Huang-Huai Mining region are selected as training samples (Table 6). The above seven influencing factors $x_{1}-x_{7}$ were used as discriminating factors, the actual state of the shaft is used as the discriminant results, and the discriminant model is established. Among the measured data selected in the paper, the shaft that is actually fractured or prematurely treated in advance is regarded as failure. According to the Fisher discriminant model, the discriminant function is as follows:

$$
\begin{aligned}
y= & 0.093397 x_{1}-0.02241 x_{2}+0.185489 x_{3}+1.017597 x_{4} \\
& +6.445895 x_{5}+5.592308 x_{6}+1.775812 x 7 .
\end{aligned}
$$

According to the discriminant function (7), the function value of each shaft is calculated. According to the Fisher discriminant calculation method, the discriminant critical value ${ }_{\mathrm{y} 0}$ is obtained from equation (6), thereby discriminating the classification of the given sample. After calculation, it is found that $y_{0}=53.11933$. Because $\bar{y}^{(1)}=56.99705$ and $\bar{y}^{(2)}=35.66959, \bar{y}^{(1)}>\bar{y}^{(2)}$, when the sample is substituted with the discriminant, if $y>y_{0}$, it will be judged as fracture while if $y<y_{0}$, it will be judged to be stable. So the criterion is

$$
\begin{cases}\text { When } y>y_{0}, & X \in \text { broken, } \\ \text { When } y<y_{0}, & X \in \text { stable, } \\ \text { When } y=y_{0}, & \text { pending. }\end{cases}
$$

The $y$ value and the judgment results of each sample are shown in Table 6. The prediction results of shaft stability in the Zhuxianzhuang Coal Mine are shown in Table 7. It can be seen from Table 6 that when the discriminant function $y$ value is greater than 53.1193, the possibility of shaft failure is large while when $y$ value is less than 53.11933, the shaft is stable. It can be seen from Table 7 that the main and auxiliary shafts in the Zhuxianzhuang Coal Mine are more likely to be destructed when drastic drawdown dewatering.

5.2.4. Discriminant Effect Verification. Verify the discriminant effect (assuming the two population covariance matrices are the same and the population obeys a normal distribution):

$$
\begin{aligned}
& H_{0}: E x_{\alpha}^{(1)}=\mu_{1}=E x_{\alpha}^{(2)}=\mu_{2}, \\
& H_{1}: \mu_{1} \neq \mu_{2} .
\end{aligned}
$$

Test statistics: 
TABLE 6: Training sample of shaft stability.

\begin{tabular}{lccccccccc}
\hline Shaft name & $x_{1}\left(\mathrm{~mm} \cdot \mathrm{a}^{-1}\right)$ & $x_{2}(\mathrm{~mm})$ & $x_{3}(\mathrm{~m})$ & $x_{4}(\mathrm{~m})$ & $x_{5}(\mathrm{~m})$ & $x_{6}$ & $x_{7}$ & Shaft state & Discriminant value $y$ \\
\hline Auxiliary shaft in the Linhuan mine & 47 & 426 & 240 & 7.2 & 0.77 & 1 & 0 & Failure & 57.243 \\
Main shaft in the Haizi mine & 60 & 503 & 247 & 6.5 & 0.8 & 1 & 1 & Failure & 59.287 \\
Auxiliary shaft in the Haizi mine & 60 & 503 & 247 & 7.2 & 0.71 & 1 & 0 & Failure & 57.643 \\
Auxiliary shaft in the Luling mine & 50 & 400 & 200 & 6.1 & 1.25 & 1 & 0 & Failure & 54.436 \\
Main shaft in the Zhangshuanglou mine & 38 & 466 & 242 & 5.5 & 0.83 & 1 & 1 & Failure & 56.309 \\
Auxiliary shaft in the Zhangshuanglou mine & 38 & 466 & 242 & 5.5 & 1 & 1 & 1 & Failure & 57.405 \\
Main shaft in the Tongting mine & 30 & 306 & 230 & 5.3 & 2.2 & 0 & 0 & Failure & 58.181 \\
Auxiliary shaft in the Tongting mine & 30 & 306 & 230 & 6.55 & 1.67 & 0 & 0 & Failure & 56.037 \\
Ventilation shaft in the Tongting mine & 30 & 306 & 230 & 5.0 & 1.11 & 1 & 0 & Failure & 56.442 \\
Main shaft in the Dongtan mine & 15.7 & 353.3 & 108.17 & 7 & 0.91 & 1 & 1 & Stable & 33.970 \\
North ventilation shaft in the Dongtan mine & 9.14 & 186.6 & 111.04 & 6 & 1.25 & 1 & 1 & Stable & 37.370 \\
\hline
\end{tabular}

Table 7: Prediction of shaft stability with drastic drawdown dewatering.

\begin{tabular}{lccccccccc}
\hline Shaft name & $x_{1}\left(\mathrm{~mm} \cdot \mathrm{a}^{-1}\right)$ & $x_{2}(\mathrm{~mm})$ & $x_{3}(\mathrm{~m})$ & $x_{4}(\mathrm{~m})$ & $x_{5}(\mathrm{~m})$ & $x_{6}$ & $x_{7}$ & Shaft state & Discriminant value $y$ \\
\hline Main shaft in the Zhuxianzhuang mine & 249.69 & 249.69 & 255.9 & 5.5 & 1.05 & 1 & 1 & Failure & 79.332 \\
Auxiliary shaft in the Zhuxianzhuang mine & 302.75 & 302.75 & 256.5 & 6.5 & 1.1 & 1 & 1 & Failure & 84.550 \\
\hline
\end{tabular}

$$
\begin{aligned}
F= & \frac{\left(n_{1}+n_{2}-2\right)-p+1}{\left(n_{1}+n_{2}-2\right) p} T^{2} H_{0} F\left(p, n_{1}+n_{2}-p-1\right), \\
T^{2}= & \left(n_{1}+n_{2}-2\right)\left[\sqrt{\frac{n_{1} n_{2}}{n_{1}+n_{2}}}\left(\bar{X}^{(1)}-\bar{X}^{(2)}\right)^{\prime} S^{-1} \sqrt{\frac{n_{1} n_{2}}{n_{1}+n_{2}}}\right. \\
& \left.\cdot\left(\bar{X}^{(1)}-\bar{X}^{(2)}\right)\right] \\
S= & \left(S_{i j}\right)_{p \times p}{ }^{n_{1}} \\
S_{i j}= & \sum_{\alpha=1}^{n_{\alpha i}}\left(X_{\alpha i}^{(1)}-\bar{X}_{i}^{(1)}\right)\left(X_{\alpha j}^{(1)}-\bar{X}_{j}^{(1)}\right)+\sum_{\alpha=1}^{n_{2}}\left(X_{\alpha i}^{(2)}-\bar{X}_{i}^{(2)}\right) \\
& \cdot\left(X_{\alpha j}^{(2)}-\bar{X}_{j}^{(2)}\right), \\
\bar{X}^{(i)}= & \left(\bar{X}_{1}^{(i)}, \ldots, \bar{X}_{p}^{(i)}\right)^{\prime} .
\end{aligned}
$$

Given the test level $\alpha$, check the $F$ distribution table and determine the critical value $F_{\alpha}$. If $F$ is greater than $F_{\alpha}$, then $H_{0}$ is negated and the discrimination is considered valid, otherwise the discrimination is considered invalid.

After calculation, the training sample $F=14.95693>$ $F_{0.05}(7,3)=8.89$.

Therefore, under the test level of $\alpha=0.05$, the difference between the two populations is significant, that is, the discriminant function is valid. The results of the judgment show that the discriminant results of each group are the same as the actual situation, and the total correct rate of the discriminant is $100 \%$, indicating that the discriminant model is reliable.

According to the evaluation results, it can be seen that the drastic drawdown dewatering of the fifth aquifer in the Zhuxianzhuang Coal Mine may cause the main and auxiliary shafts failure. Therefore, it is necessary to take some preventive measures in advance. Grouting the surrounding strata plays an active role in improving the state of aquifer. The advantage is that it can be carried out without a section in the shaft, and the service life of the shaft is long after treatment. Through the ground grouting, the aquifer condition is improved, the formation compression is reduced, and the stress state of the shaft wall is alleviated. Therefore, it is recommended to use the technology of grouting the surrounding strata to prevent shaft failure in the Zhuxianzhuang Coal Mine in advance.

\section{Conclusions}

Shaft is the throat of a coal mine. The stability of the shaft is related to the safety of personnel and economic benefits of the coal mine. With the increasing number of shaft failure caused by the hydrophobicity of strata, a disaster of nonmining failure of the shaft has attracted the attention of more and more researchers and engineers. In the paper, taking the Zhuxianzhuang Coal Mine as an example, based on the methods of measured analogy, numerical simulation, and Fisher discriminant model, the stability of the shaft is evaluated under the condition of drastic drawdown dewatering.

According the measured data of compression ratio of strata in the adjacent Xinglongzhuang Coal Mine and the simulation results of water level drop by GMS, the stability of the main and auxiliary shafts in the Zhuxianzhuang Coal Mine are predicted. The compressive amounts of strata near the main and auxiliary shafts are predicted to be $249.69 \mathrm{~mm}$ and $302.75 \mathrm{~mm}$, respectively. The numerical simulation of the NM2dc model shows that the vertical stress of the shaft wall at the bottom of alluvium reaches $40 \mathrm{MPa}$ (fourth load level) and $70 \mathrm{MPa}$ (fifth load level), which exceeds the strength of the shaft wall and indicates that the possibility of the shaft failure is large. The compressive amounts of strata are approximately $150 \mathrm{~mm}$ and $180 \mathrm{~mm}$, respectively. The compressive amount of strata is predicted approximately 
$320 \mathrm{~mm}$ (ninth load level) in one year, which is generally consistent with the predicted by measured strata compression in the adjacent Xinglongzhuang Coal Mine. The Fisher discriminant model is established by selecting seven main factors that affect the shaft failure. According to the criterion model, the stability of the main and auxiliary shafts in the Zhuxianzhuang Coal Mine is evaluated, and it is concluded that the main and auxiliary shaft walls are more likely to fracture under the condition of drastic drawdown dewatering in one year.

Based on the evaluation results, the technical means of using the ground grouting for early prevention and control is proposed. In future work, we will establish a strain monitoring system of shaft and study the mechanism and effect of the ground grouting to prevent shaft failure by means of laboratory, numerical simulation, and field test.

\section{Data Availability}

All data included in this study are available upon request by contact with the corresponding author.

\section{Conflicts of Interest}

The authors declare no conflicts of interest.

\section{Authors' Contributions}

Mingze $\mathrm{Du}$ and Yanchun $\mathrm{Xu}$ conceptualized the study. Yanchun $\mathrm{Xu}$ developed methodology. Mingze $\mathrm{Du}$ and Yanchun $\mathrm{Xu}$ were responsible for software. Heng Duan performed formal analysis. Mingze Du and Heng Duan carried out investigation. Heng Duan was involved in data curation. Mingze Du performed English editing. Wen Li and Mingze $\mathrm{Du}$ were responsible financial support.

\section{Acknowledgments}

This research was funded by the National Science and Technology Major Project of China (Grant nos. 2016ZX05045001-004), China Coal Research Institute Science and Technology Innovation Fund (Grant no. 2019CXII-13), and National Natural Science Foundation of China (Grant no. 51804162). The authors are grateful for their support.

\section{References}

[1] X. H. Ni, Y. C. Xu, and T. F. Wang, Mechanism and Prevention of Shaft Fracture in Thick Alluvium, China Coal Industry Publication House, Beijing, China, 2007.

[2] G. X. Cui, "Mechanism and prevention of shaft fracture in special stratum," Mine Construction Technology, vol. 19, no. 1, pp. 28-32, 1998.

[3] G. X. Cui and X. L. Cheng, "Occasions of damaging shaft walls in the Xuhuai district," Coal Science and Technology, vol. 12, no. 8, pp. 46-50, 1991.

[4] H. Cheng, J. Su, and R. S. Tang, "Fuzzy inversion of negative friction on shaft walls in subsiding stratum induced by drainage," Journal of Xi'an Mining Institute, vol. 19, no. 4, pp. 309-312, 1999.
[5] X. H. Ni, W. H. Sui, and Y. Z. Guan, Control Techniques of Shaft Wall Fracture in Coal Mine, China University of Mining and Technology Press, Xuzhou, China, 2005.

[6] W. C. Wang, "Strength analysis of shaft based on surface subsidence caused by thick alluvium draining," Journal of China University of Mining and Technology, vol. 25, no. 3, pp. 54-58, 1996.

[7] H. Y. Liu, W. Z. Chen, and Z. M. Wang, "Theoretical analysis of shaft lining damage mechanism of Yanzhou mine," Chinese Journal of Rock Mechanics and Engineering, vol. 26, no. S1, pp. 2620-2626, 2007, in Chinese.

[8] W. Q. Zhang, Y. H. Lu, H. Y. Gong, X. Y. Meng, and Y.Z. Guan, "Causes analysis of shaft wall damage in Yan-Teng mining district and its prevention and controlling method," Rock and Soil Mechanics, vol. 25, no. 12, pp. 1977-1980, 2004.

[9] G. D. Lou and L. F. Su, "Analysis of loading on shaft lining subjected to alluvium settlement due to water drainage," Journal of China Coal Society, vol. 16, no. 4, pp. 54-61, 1991.

[10] S. C. Wang and H. Z. Ge, "Causes and preventions of shaft wall fracturing in Yanzhou mining area," Journal of China University of Mining and Technology, vol. 28, no. 5, pp. 494-498, 2007.

[11] W. Hu and W. H. Sui, "Three-dimensional numerical analysis of treatment efficiency for ruptured shaft due to strata dewatering settlement," Rock and Soil Mechanics, vol. 32, no. S1, pp. 743-748, 2011.

[12] W. Q. Zhang, Y. S. Zhang, J. D. Xi, and Y. Z. Guan, "The mechanism of sidewall cracking in vertical well of coal mine and its prevention countermeasures," The Chinese Journal of Geological Hazard and Control, vol. 12, no. 4, pp. 13-17, 2001.

[13] Y. C. Xu, X. D. Li, and Y. X. Jie, "Test on water-level stabilization and prevention of mine-shaft failure by means of groundwater injection," Geotechnical Testing Journal, vol. 37, no. 2, article 20130027, 2014.

[14] S. Q. Liu, Y. X. Jie, and Y. C. Xu, "Prevention of mine-shaft failure by aquifer replenishment," Journal of Testing and Evaluation, vol. 45, no. 3, article 20150203, 2017.

[15] X. L. Deng, C. C. Jiang, Y. C. Xu, J. H. Li, and L. M. Liang, "Analysis on effect of automatic water refilling method," Coal Engineering, vol. 46, no. 12, pp. 32-34, 2014.

[16] J. H. Huang and W. H. Yang, "Study on variation of vertical additional force on shaft lining by simulation tests," Chinese Journal of Geotechnical Engineering, vol. 28, no. 10, pp. 1204-1207, 2006.

[17] J. H. Huang, W. H. Yang, F. Li, and Z. S. Wang, "Field measurement research on temperature changing law of vertical shaft lining," Journal of Liaoning Technical University, vol. 26, no. 3, pp. 360-362, 2007.

[18] Z. Q. Meng, H. G. Ji, and F. Peng, "Additional stress of shaft linings in thick alluvium constructed by freezing process," Journal of China Coal Society, vol. 38, no. 2, pp. 204-208, 2013.

[19] H. C. Liang, G. Q. Zhou, Z. Q. Liu, J. S. Zhou, and G. S. Zhao, "An in-situ long period observation of additional strain in shaft linings," Journal of China University of Mining \& Technology, vol. 38, no. 6, pp. 794-799, 2009.

[20] H. C. Liang, G. Q. Zhou, and Z. Q. Liu, "In-situ tests on ground surface settlement and additional strain of shaft linings," Chinese Journal of Geotechnical Engineering, vol. 32, no. 6, pp. 924-929, 2010.

[21] Y. Xu, M. Du, and Y. Luo, "Using water injection to prevent shaft failure in the Jining no. 3 coal mine, China," Mine Water and the Environment, vol. 38, no. 1, pp. 60-71, 2019.

[22] J. Chai, L. Zhu, D. D. Zhang et al., "Study on settlement deformation of unconsolidated strata during low-pressure 
water injectin process of multi-borehole," Journal of China Coal Society, vol. 38, no. 10, pp. 1720-1727, 2013.

[23] J. Baek, S.-W. Kim, H.-J. Park, H.-S. Jung, K.-D. Kim, and J. W. Kim, "Analysis of ground subsidence in coal mining area using SAR interferometry," Geosciences Journal, vol. 12, no. 3, pp. 277-284, 2008.

[24] H. P. Sato, K. Abe, and O. Ootaki, "GPS-measured land subsidence in Ojiya city, Niigata prefecture, Japan," Engineering Geology, vol. 67, no. 3-4, pp. 379-390, 2003.

[25] P. R. Sheorey, J. P. Loui, K. B. Singh, and S. K. Singh, "Ground subsidence observations and a modified influence function method for complete subsidence prediction," International Journal of Rock Mechanics and Mining Sciences, vol. 37, no. 5, pp. 801-818, 2000.

[26] F. G. Bell, S. E. T. Bullock, T. F. J. Hälbich, and P. Lindsay, "Environmental impacts associated with an abandoned mine in the Witbank Coalfield, South Africa," International Journal of Coal Geology, vol. 45, no. 2-3, pp. 195-216, 2001.

[27] Y. Luo, R. Kimutis, K. Yang, and J. W. Cheng, "Mitigation of longwall subsidence effects on an operating railroad," in Proceedings of the 29th International Conference on Ground Control in Mining, pp. 89-96, Morgantown, WV, USA, July 2010.

[28] A. K. Soni, K. K. K. Singh, A. Prakash, K. B. Singh, and A. K. Chakraboraty, "Shallow cover over coal mining: a case study of subsidence at Kamptee Colliery, Nagpur, India," Bulletin of Engineering Geology and the Environment, vol. 66, no. 3, pp. 311-318, 2007.

[29] B. Unver and N. E. Yasitli, "Modelling of strata movement with a special reference to caving mechanism in thick seam coal mining," International Journal of Coal Geology, vol. 66, no. 4, pp. 227-252, 2006.

[30] T. Ambrožič and G. Turk, "Prediction of subsidence due to underground mining by artificial neural networks," Computers \& Geosciences, vol. 29, no. 5, pp. 627-637, 2003.

[31] Y. C. Xu, X. H. Ni, R. X. Liu, and G. Y. Zhang, "Safety assessment and breaking prediction system of mine shaft," Coal Science and Technology, vol. 34, no. 7, pp. 69-71, 2006.

[32] Y. C. Xu, Y. B. Gao, J. H. Li, and W. Z. Gu, "Improvement and application of mine shaft safety evaluation system," Coal Science and Technology, vol. 44, no. 10, pp. 95-101, 2016, in Chinese.

[33] C. L. Liu, Y. Li, and Y. C. Xu, "Stability appraisal and fracture forecast of coal mine shaft," Coal and Chemical Industry, vol. 36, no. 11, pp. 13-16, 2013.

[34] F. Q. Gong and X. B. Li, "A distance discriminant analysis method of forecast for shaft-lining non-mining fracture of mine," Journal of China Coal Society, vol. 32, no. 7, pp. 700-704, 2007.

[35] L. B. Shao and Y. Zhang, "Forecast for non-mining fracture of shaft-lining of mine," Journal of China Coal Society, vol. 34, no. 2, pp. 184-186, 2009.

[36] Z. G. Yuan, H. T. Wang, G. Z. Hu, N. P. Liu, and X. G. Fan, "Forecast model of GA-SVM for shaft-lining non-mining fracture," Journal of China Coal Society, vol. 36, no. 3, pp. 393-397, 2011. 


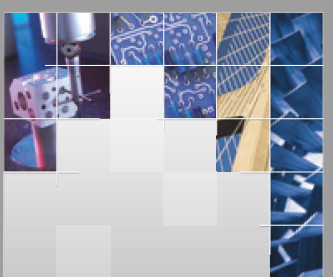

\section{Enfincering}
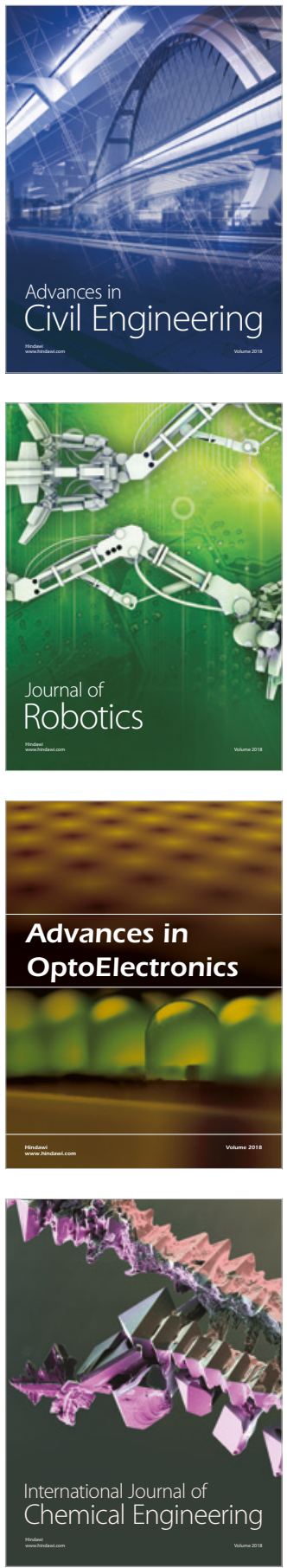

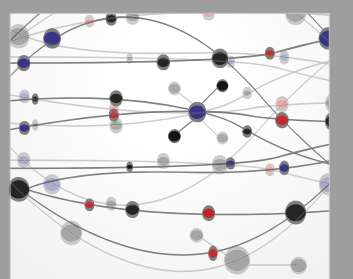

\section{Rotating \\ Machinery}

The Scientific World Journal

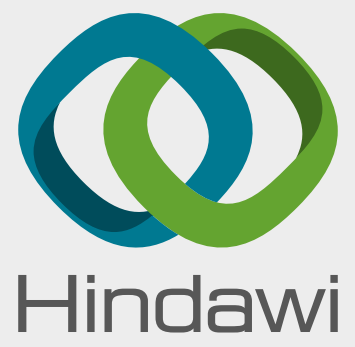

Submit your manuscripts at

www.hindawi.com
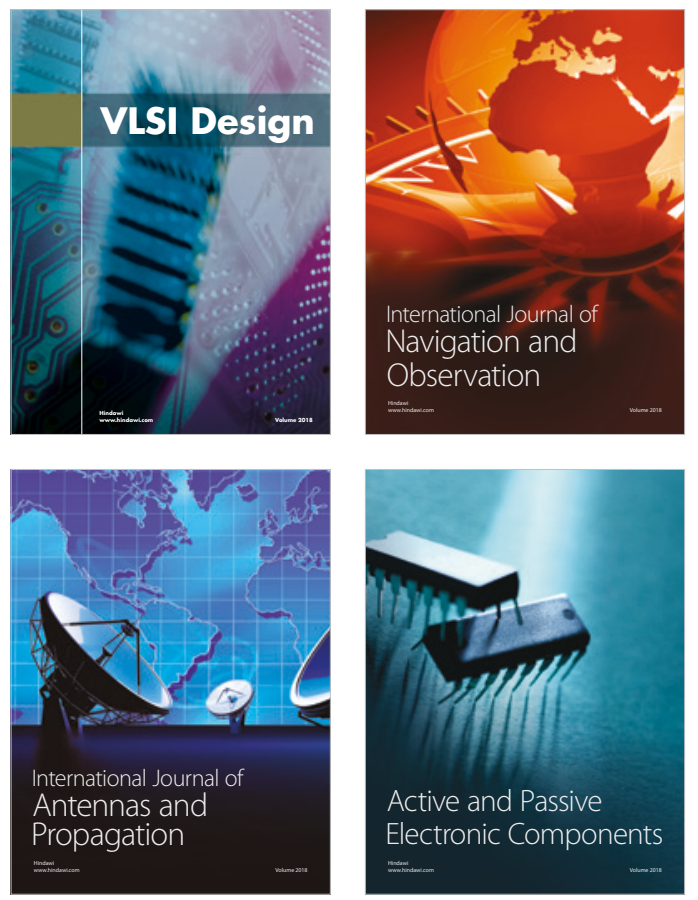
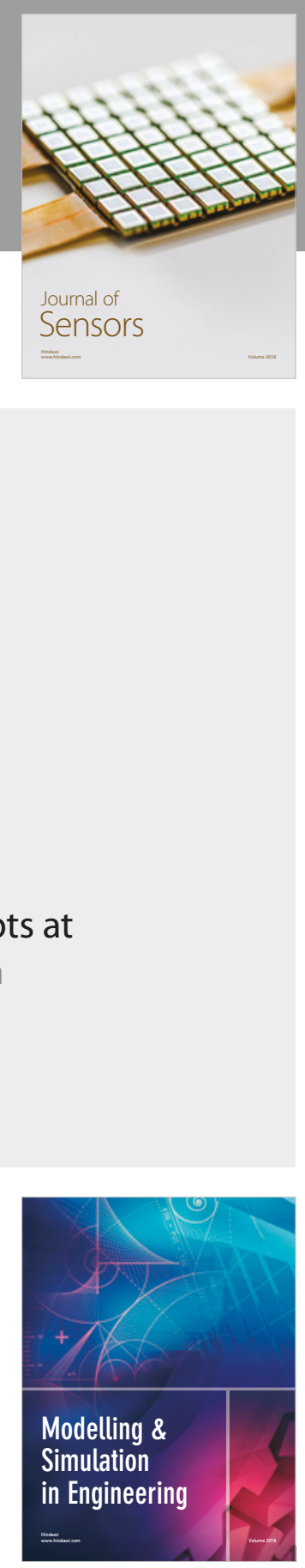

\section{Advances \\ Multimedia}
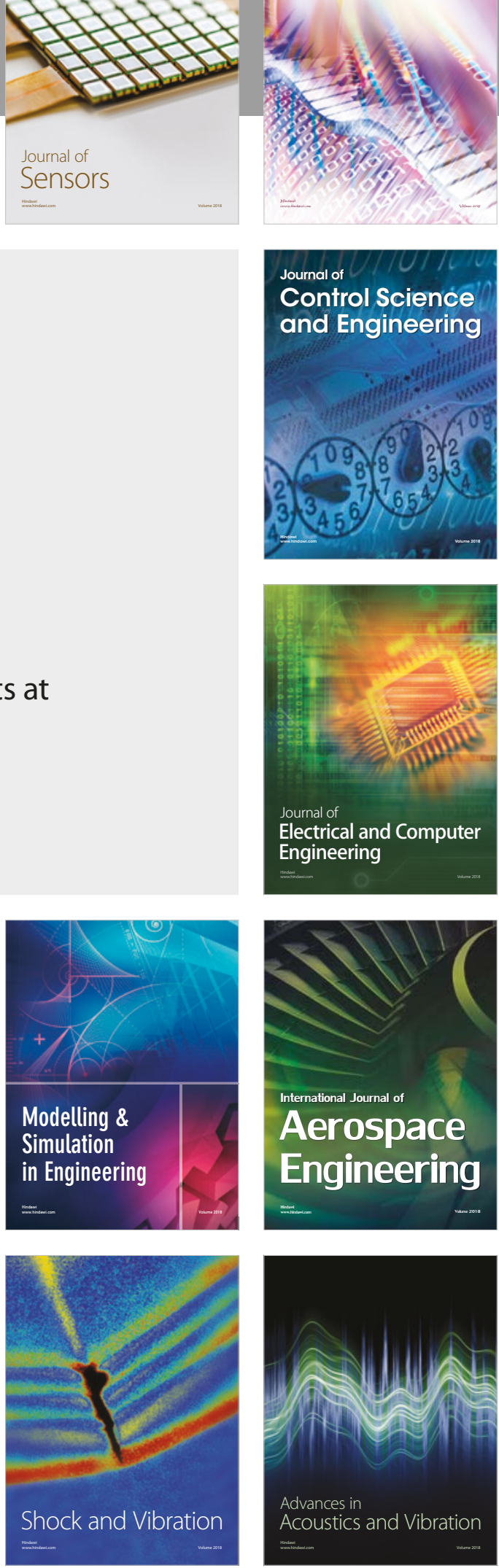